\title{
Optimal Decision-Making of Vertical Relationship Governance in China's Coal-electricity Energy Supply Chain
}

\author{
Qiang Wang ${ }^{1, \mathrm{a}}$, Haiying Liu ${ }^{* 2, \mathrm{~b}}$, Xin Liu ${ }^{3, \mathrm{c}}$, Jiaxin Wang and Jiaoyu He $\mathrm{H}^{4, \mathrm{~d}}$ \\ ${ }^{1}$ Affilication: Department of Mechanical and Traffic Engineering, Ordos Institute of Technology, Ordos, China \\ ${ }^{2}$ Affilication: Department of Management, Ordos Institute of Technology Ordos, China \\ ${ }^{3}$ Affilication: School of Finance and taxation, Inner Mongolia University of Finance and Economics, Hohhot, China \\ ${ }^{4}$ Affilication: School of Finance and taxation, Inner Mongolia University of Finance and Economics, Hohhot, China
}

\begin{abstract}
Coal and coal-fired electricity generation, as interdependent upstream and downstream industries, play a positive role in ensuring energy security, economic development and social stability in China. However, the strategies of coal enterprises and coal-fired power enterprises are influenced by the market structure, coalelectrical energy policies and the characteristics in the coal-electricity energy supply chain. In this paper, considering the upstream for many coal enterprises, the downstream for many coal-fired electricity generation enterprises in coal-electricity energy supply chain model, is concluded that profit calculation model for coalelectricity cooperative enterprises, independent upstream coal enterprises, and independent downstream coalfired electricity generation enterprises were obtained. In order to maximize the profits, we construct coal enterprises and coal-fired electricity generation enterprises cooperative operation decision-making model, and the different situation of the optimal strategy is studied and analyzed. Using Matlab simulation software for numerical simulation. It is to belong to the simulation results confirm the efficiency of the model.
\end{abstract}

\section{Introduction}

Considering the increasing number of energy consumption, a large number of coal enterprises and coalfired electricity generation enterprises in coal-electricity energy supply chain are facing increasingly serious problems of supply coordination. Due to the unsynchronization of the coal marketization reform and the electric power marketization reform, the price conflict between coal enterprises and coal-fired electricity generation enterprises in the coal-electricity energy supply chain. Then, how to solve the price conflict between coal enterprises and coal-fired electricity generation enterprises has become a hot issue concerned by the government, enterprises and society $[1,2,3,4]$.

\section{Related Work}

The asymmetry of Chinese coal and electricity price reforms leads to serious conflict between coal enterprises and coal-fired power generation enterprises. When the electric power price is certain, and coal prices rise sharply, coal-fired power generation enterprises face significant losses, at the same time, they will also lead to uncertainty in the quantity and quality of coal supplies. Yang et al. taking China coal Pingshuo group co., ltd. as the research object, it is found that coal integration can improve the economic benefits of enterprises [5]. Peng et al. discusses the establishment of cooperative relationship between coal suppliers and power companies to solve conflicts [6]. Studies the mixture of vertical integration and vertical separation, points out the coexistence of vertical integration and vertical separation in the market $[7,8]$. Many scholars explore the application of vertical integration and vertical separation models. Felix et al. the optimal split model of vertical split of supply chain by law regulation is studied [9].

In this paper, based on the principle of vertical integration, coal-electricity power energy policy and the characteristics in the coal-electricity energy supply chain, analyzes the best strategy and reasons of coal enterprises and coal-fired electricity generation enterprises under the market structure in the coal-electricity energy supply chain. we develop the coal-electricity cooperative decision-making model. propose the optimal decisionmaking of vertical relationship governance in China's coal-electricity energy supply chain. Finally, use of Matlab simulation software for numerical simulation, we present the optimal decision-making method, and we can get the maximum profit of each in coal-electricity energy supply chain under different scenarios. At last, the simulation results verify the effectiveness of our proposed model.

\footnotetext{
amail: edwangqiang@163.com

bEmail: 1hy_liuhaiying@163.com, ${ }^{*}$ Correspondence: lhy_liuhaiying@163.com, Tel.: +86-186-8623-7979/0477-8591194

cEmail: 3092076139@qq.com, ${ }^{\mathrm{d} E m a i 1:} 422612339 @ q q . c o m$ and 3544378722@qq.com
} 


\section{Model}

There is a coal-electricity energy supply chain, including $\mathrm{n}$ upstream coal enterprises and $\mathrm{m}$ downstream coal-fired electricity generation enterprises, and the upstream coal enterprises supply coal to the downstream coal-fired electricity generation enterprises, where $n \geq 2, m \geq$ 2.The fixed production cost of upstream coal enterprises is FC, and the marginal production cost is $\mathrm{d}$. The fixed production cost of downstream coal-fired electricity generation enterprises is $\mathrm{FE}$, the marginal production cost is $\mathrm{g}$, and the coal sales price in the upstream coal market is $\omega$.

To facilitate research, this article assumes that the production cost of $\mathrm{n}$ upstream coal companies is the same, the production cost of $\mathrm{m}$ downstream coal-fired electricity generation enterprises is the same, also including $\mathrm{k}$ coalelectricity cooperative enterprises. Here and below, superscripts $\mathrm{C}, \mathrm{E}$ and $\mathrm{V}$ represent upstream coal enterprises, downstream coal-fired electricity generation enterprises and coal-electricity cooperative enterprises. The output of a coal-electricity cooperative enterprise is $q_{t}^{V}$, and the total output is $Q^{V}=k q_{t}^{V}$, where $t=1,2, \ldots, k$. Same goes for other things.

Assuming that all participants in the market sell and buy at an equilibrium price, and each market is completely cleared, there is $Q^{C}=\beta Q^{E}, Q=Q^{V}+Q^{E}$, where $\beta$ is the standard electricity generation per unit coal. The inverse demand function of downstream coal-fired electricity generation enterprises is:

$$
p=r-s Q=r-s\left(Q^{V}+Q^{E}\right)
$$

Where $r>0, s>0, p$ and $Q$ are respectively the price and demand of downstream coal-fired electricity generation enterprises. According to the Cournot game model, the profit function of coal-electricity cooperative enterprise and coal-fired electricity generation enterprise in the downstream is given as follows:

$$
\begin{gathered}
\xi_{t}^{V}=\left[r-s\left(Q^{V}+Q^{E}\right)-g-\beta d\right] q_{t}^{V}-F^{C}-F^{E} . \\
\xi_{j}^{E}=\left[r-s\left(Q^{V}+Q^{E}\right)-g-\beta w\right] q_{j}^{E}-F^{E}
\end{gathered}
$$

After the formula derivation finally get the corresponding profits is:

Coal-electricity cooperative enterprise:

$$
\begin{aligned}
& \xi_{t}^{V}=\frac{1}{s(m+1)^{2}}\left[1+\frac{m-k}{(k+1)(n-k+1)}\right]^{2}(r-\beta d-g)^{2}- \\
& F^{C}-F^{E}
\end{aligned}
$$

Independent upstream coal enterprise:

$\xi_{i}^{C}=\frac{m-k}{s(m+1)(k+1)(n-k+1)^{2}}(r-\beta d-g)^{2}-F^{C}$

Independent downstream coal-fired enterprise:

$$
\xi_{j}^{E}=\frac{1}{s}\left[\frac{n-k}{(m+1)(n-k+1)}\right]^{2}(r-\beta d-g)^{2}-F^{E}
$$

\section{Analysis}

When the profit of coal-electricity cooperative operation is larger than the profit of independent operation, coal- fired electricity generation enterprises will choose coalelectricity cooperative operation. In the coal-electricity energy supply chain, it is assumed that the enterprise in a competitive advantage decides whether to cooperative operation or independent operation. When $m \geq n \geq 2$, the $\mathrm{E}$ depends on the $\mathrm{C}$, the $\mathrm{C}$ decides whether to cooperative the $\mathrm{E}$, and $\mathrm{E}$ decides whether to accept cooperative operation or independent operation, and vice versa. The coal-electricity cooperative decision-making model of coal-electricity cooperative enterprise is:

$$
\begin{array}{r}
\Delta \xi=\xi_{t}^{V}-\left(\xi_{i}^{C}+\xi_{j}^{E}\right)=\frac{-k^{2}+(2 n-m-1) k+2 n-1}{s(m+1)(k+1)^{2}(n-k+1)}(r-\beta d- \\
g)^{2}
\end{array}
$$

According to the assumed conditions $\frac{(r-\beta d-g)^{2}}{s}>0$,

$(m+1)>0,(k+1)^{2}>0,(n-k+1)>0$, the symbol of equation (17) can be simplified to:

$$
X=-k^{2}+(2 n-m-1) k+2 n-1
$$

Since the value of $\mathrm{X}$ can be positive or negative, the profit of coal-electricity cooperative enterprise may increase or decrease.

\subsection{Positive income situation}

When $2 \leq m \leq n$ and $k=1,2, \ldots m, X>0$.

(1) If $k=1, X$ is the maximum, that is:

$$
\overline{X_{\max }}=4 n-m-3>0
$$

(2) If $k=m, X$ is the minimum, that is:

$$
\overline{X_{\min }}=\frac{-2 m^{2}+(2 n-1)(m+1)}{m}
$$

As the profit of coal-electricity cooperative operation is larger than that of coal-electricity independent operation, $\mathrm{m}$ upstream coal enterprises engage coalelectricity cooperative operation for downstream coalfired electricity generation enterprises, $n-m$ upstream coal enterprises withdraw without coal product supply market, and upstream and downstream enterprises fully cooperative operation, forming an oligopoly industry chain.

\subsection{Uncertain income situation}

When $n<m \leq 4 n-3 \quad, \quad 1 \leq k \leq k_{\text {max }} \quad, \quad k=$ $1,2, \ldots n X \geq 0$ or $k_{\max } X \leq 0$.

If $k=1 X$ is the maximum, that is:

$$
\overline{X_{\max }}=4 n-m-3>0
$$

If $k=n, X$ is the minimum, that is

$$
\overline{X_{\min }}=\frac{n^{2}-m m+n-1}{n}
$$

When $m$ increases greatly, $m-n$ coal-electric independent enterprises produce a larger output, which makes a greater contribution to the output of upstream coal enterprises. Attract coal-electricity cooperative 
enterprises to split off the downstream coal-fired electricity generation enterprises with large supply, although their profit margins have been reduced, their output has increased significantly, and their total profit has also increased. At this time, the formation of coalelectricity cooperative operation enterprises and coalelectricity independent operation enterprises coexistence.

\subsection{Negative income situation}

When $4 n-3<m, k=0, X<0$, The profit of coalelectricity cooperative operation is less than that of coalelectricity independent operation, so the upstream and downstream industry separation, no coal-electricity cooperative operation.

\section{Simulation}

\subsection{Positive income situation}

In the case of positive income situation, each parameter is assumed as follows: $\mathrm{n}=25, \mathrm{~m}=20$, at this time, $2 \leq m \leq n$ According to parameter settings, $\bar{X}$ change with $\mathrm{k}$ in figure 1.

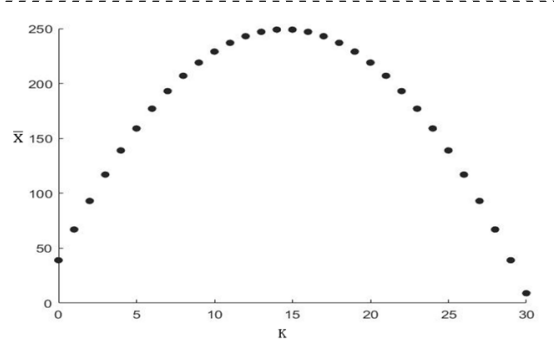

Fig 1. $\bar{X}$ change with $\mathrm{k}$ in positive income situation

At this time, upstream and downstream enterprises forming an oligopoly industry chain.

\subsection{Uncertain income situation}

In the case of uncertain income situation, the parameters are assumed as follows: $\mathrm{n}=25, \mathrm{~m}=40$, at this time $n<m \leq$ $4 n-3$.

According to parameter Settings, $\bar{X}$ changes with $\mathrm{k}$ value on values is shown in figure 2 .

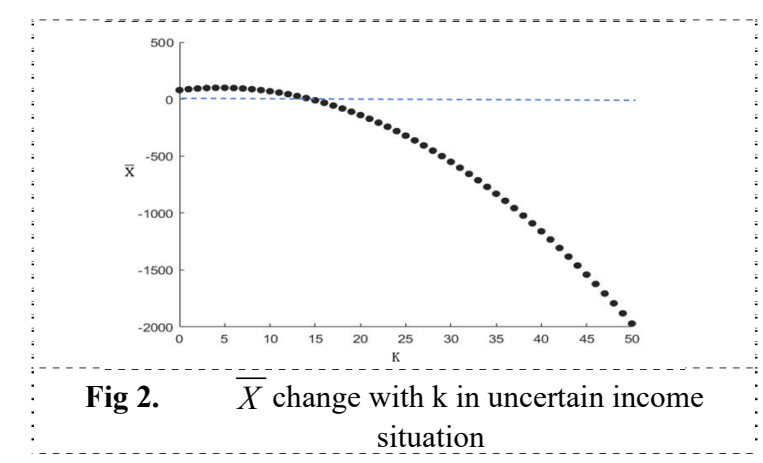

At this time, coal-electricity cooperative enterprise and coal-electricity independent enterprise coexistence.

\subsection{Negative income situation}

In the case of negative income situation, each parameter is assumed as follows: $\mathrm{n}=10, \mathrm{~m}=50$, at this time $4 n-3<$ $m$. According to parameter Settings, $\bar{X}$ changes with $\mathrm{k}$ value on values is shown in figure 3 .

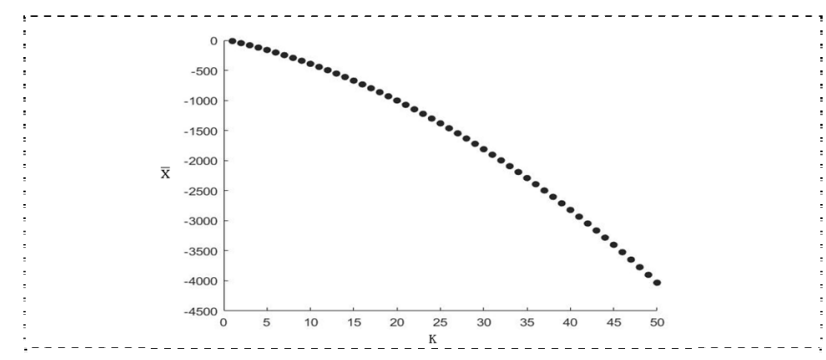

Fig 3. $\bar{X}$ change with $\mathrm{k}$ in negative income situation

The profit of coal-electricity cooperative operation less than that of coal-electricity independent operation. When coal-electricity cooperative enterprise loss, in this situation, the formation of complete coal-electricity independent operation.

\section{Conclusions}

The analysis results of this paper are as follows.

A. From the market structure in the coal-electricity energy supply chain, can draw the following conclusions:

At the early stage of marketization reform, there are a large number of upstream coal enterprises and a large number of downstream coal-fired electricity generation enterprises stimulated by electricity demand, which is the coal-electricity energy market of complete coal-electricity cooperative enterprises. At the period of reducing capacity policy, the upstream coal enterprises will make the best decision of coal-electricity cooperative operation or independent operation according to the number of upstream coal enterprises, downstream coal-fired electricity generation enterprises and coal-electricity cooperative operation enterprises in the market.

B. From the perspective of coal-electricity energy policy in the coal-electricity energy supply chain, can draw the conclusion that, the complete coal-electricity independent operation gradually evolved into partial coalelectricity cooperative operation.

C. From the perspective of the characteristics in the coal-electricity energy supply chain, when the upstream coal enterprises cooperation with the downstream coalfired electricity generation enterprises, the cost of the cooperative can be reduced and the market competitiveness of the cooperative can be enhanced.

\section{Acknowledgments}

This work was supported by Research Program of Science and Technology at Universities of Inner Mongolia 
Autonomous Region(NJSY19262); Natural Science Foundation of Inner Mongolia Autonomous Region of China(2019MS07005,2019MS07006); "Young Talents in Science and Technology" in Higher Education Institutions in Inner Mongolia Autonomous Region of China(NJYT-20-A19); Innovative talent team project for ecological restoration and high-quality development of cultural tourism industry in Ordos; Talent Development Fund Project in Inner Mongolia Autonomous Region of China([2019]114); Inner Mongolia Social Science Foundation Project (20B64).

\section{References}

1. Fan, J.L., Ke R.Y., et al. How does coal-electricity price linkage impact on the profit of enterprises in China? Evidence from a Stackelberg game model. Resources Conservation and Recycling. 2016.129, 383-391.

2. Niu, D.X., Song Z.Y., et al. Electric power substitution for coal in China: Status quo and SWOT analysis. Renewable \& Sustainable Energy Reviews, 2017, 70, 610-622.

3. Peng, H., M. Zhou, et al. Multiperiod Coordination Models of Coal-Electricity Supply Chain with Double Price Regulations. Discrete Dynamics in Nature and Society.2015.

4. Li, H.Z., Tian X.L., et al. Impact analysis of coalelectricity pricing linkage scheme in China based on stochastic frontier cost function. Applied Energy.2015, 151: 296-305.

5. Yang Y., Xu J., Liu P, et.al. Application of coal and electricity joint production. Research Policy, 2018, (4), 1-25.

6. Guo Z. Y., Zhou M. H., Peng H. J. Financing strategies for coal-electricity supply chain under yield uncertainty[J].International Journal of Mining Science and Technology,2018,28(2), 353-358.

7. Jos J. Coexistence of strategic vertical separation and integration $[\mathrm{J}]$. International Journal of Industrial Organization. 2003,21(5),699-716.

8. Fiocco R. The strategic value of partial vertical integration [J]. European Economic Review. 2016, 89(11), 284-302.

9. Felix H., Sebastian K. Legal unbundling can be a golden mean between vertical integration and ownership separation [J]. International Journal of Industrial Organization. 2011,29(5), 576-588. 